\title{
Mating Interest Improves Women's Accuracy in Judging Male Sexual Orientation
}

Psychological Science 22(7) 88I-886 (c) The Author(s) 2011 Reprints and permission: sagepub.com/journalsPermissions.nav DOI: | 0.1 | 777/09567976| |4|2394 http://pss.sagepub.com @SAGE

\author{
Nicholas O. Rule', Katherine S. Rosen ${ }^{2}$, Michael L. Slepian², and \\ Nalini Ambady ${ }^{2}$ \\ 'University of Toronto and ${ }^{2}$ Tufts University
}

\begin{abstract}
People can accurately infer others' traits and group memberships across several domains. We examined heterosexual women's accuracy in judging male sexual orientation across the fertility cycle (Study I) and found that women's accuracy was significantly greater the nearer they were to peak ovulation. In contrast, women's accuracy was not related to their fertility when they judged the sexual orientations of other women (Study 2). Increased sexual interest brought about by the increased likelihood of conception near ovulation may therefore influence women's sensitivity to male sexual orientation. To test this hypothesis, we manipulated women's interest in mating using an unobtrusive priming task (Study 3). Women primed with romantic thoughts showed significantly greater accuracy in their categorizations of male sexual orientation (but not female sexual orientation) compared with women who were not primed. The accuracy of judgments of male sexual orientation therefore appears to be influenced by both natural variations in female perceivers' fertility and experimentally manipulated cognitive frames.
\end{abstract}

\section{Keywords}

sexual orientation, social perception

Received I2/I7//0; Revision accepted 3/22/II

Recent evidence has shown that perceivers are capable of extracting information from the nonverbal behaviors and appearance of other people. Teachers' nonverbal behaviors predict their students' and principals' evaluations (Ambady \& Rosenthal, 1993), facial maturity predicts job opportunities and court verdicts (Collins \& Zebrowitz, 1995; Zebrowitz \& McDonald, 1991), and inferences of personality from faces can predict leaders' success in business and politics (Rule \& Ambady, 2010). One domain in which perceivers are particularly efficient is categorizing people according to group memberships (Macrae \& Bodenhausen, 2000). Perceivers effortlessly categorize people according to age, race, and gender, in part because the physical characteristics distinguishing these groups are somewhat obvious (Brewer, 1988). Yet perceivers also have a capacity to categorize people according to characteristics that are not as visually obvious, such as sexual orientation (Ambady, Hallahan, \& Conner, 1999). In the study reported here, we explored one factor that might influence judgments of other people - sexual interest - in a particular domain - judgments of sexual orientation.

Previous work has found that sexual orientation can be judged with surprising accuracy by guessing from facial cues.
Both male and female sexual orientation were judged significantly better than chance when participants viewed faces for as little as $40 \mathrm{~ms}$ (e.g., Rule, Ambady, \& Hallett, 2009). One question that arises from these demonstrations of accuracy concerns individual differences. Regarding sexual orientation, gay men tend to make more accurate judgments than do straight men (Rule, Ambady, Adams, \& Macrae, 2007). This could be because gay men are more attentive to differences in targets' sexual orientations or because gay men have more expertise judging sexual orientation. These hypotheses are common to theories of in-group effects in perception and memory (Sporer, 2001). For instance, individuals perform better at distinguishing emotions from the faces of in-group versus out-group members (Elfenbein \& Ambady, 2003).

Yet there are also group- and individual-level variations in judging nonverbal behavior that are not directly related to ingroup effects. Women tend to be better judges of nonverbal

\section{Corresponding Author:}

Nicholas O. Rule, Department of Psychology, University of Toronto, $100 \mathrm{St}$. George St., Toronto, Ontario, Canada M5S 3G3

E-mail: rule@psych.utoronto.ca 
behavior than men are (e.g., Hall \& Andrzejewski, 2008), and extraverts are often better judges of other peoples' traits than are introverts (Lieberman \& Rosenthal, 2001). In the domain of deception detection, people are slightly but significantly more accurate than chance in judgments of deception from nonverbal cues (Bond \& DePaulo, 2006), but there is considerable interindividual variation in this ability (Bond \& DePaulo, 2008).

One biological factor known to exert an influence on perceptions of other people is variation in women's fertility cycles. Women have been found to categorize male faces faster than female faces at periods of high fertility (around ovulation) compared with periods of nonfertility (Johnston, Arden, Macrae, \& Grace, 2003; Macrae, Alnwick, Milne, \& Schloerscheidt, 2002). Similarly, women nearer ovulation rated masculinized faces (Penton-Voak et al., 1999) and masculine body gaits (Provost, Troje, \& Quinsey, 2008) as more attractive. These effects did not apply to men, women using systemic contraceptive medication, and pregnant women (Johnston et al., 2003). Moreover, lesbian women actually showed opposite effects: They categorized female faces faster than male faces during high fertility (Brinsmead-Stockham, Johnston, Miles, \& Macrae, 2008). Attention to sexually relevant targets thus varies depending on women's fertility status, and women's fertility can have multiple effects on social perception (Jones et al., 2008).

It seems reasonable, then, that women's accuracy in judging male sexual orientation might also depend on fertility cycles and sexual relevance. We therefore tested heterosexual women's accuracy in judging sexual orientation across the fertility cycle; our hypothesis was that accuracy for male faces would be greater nearer to peak ovulation (Study 1) but that ovulation would not affect the categorization of sexually irrelevant women's faces (Study 2). Finally, we examined whether increasing women's sexual interest through cognitive priming might increase their accuracy in judging sexual orientation, just as natural variations in sexual interest are brought on by the fertility cycle (Study 3).

\section{Study I}

Although it is fairly well established that fertility influences women's attention to sexually relevant cues, it is not known whether this increased attention might also benefit the accuracy of person judgments. In Study 1, we therefore asked heterosexual women to judge sexual orientation from men's faces, and we related the women's accuracy to their fertility status.

\section{Method}

Participants. Forty heterosexual undergraduate women responded to an advertisement requesting female undergraduates not using systemic contraceptive medication to participate in a psychology study in exchange for monetary compensation. Respondents verified that they were not using any contraceptive medications at the time of scheduling and at the end of their respective experimental sessions. One participant reported irregular cycles and was excluded from analysis.

Stimuli. Photos of faces of self-identified gay men $(n=40)$ and straight men $(n=40)$ were taken from a stimulus set validated in earlier studies (Rule et al., 2007; Rule, Ambady, Adams, \& Macrae, 2008). The photos were gray-scale images standardized for size, and none of the targets had adornments (e.g., jewelry, facial hair). Moreover, the gay and straight men did not differ in emotional expression or attractiveness (see Rule et al., 2008, for details).

Procedure. Participants were instructed that they would view men's faces on a computer screen and would be asked to indicate each man's probable sexual orientation as gay or straight by pressing a key. Participants were encouraged to use their intuition in making judgments and not to think about any one face too much. Afterward, the women volunteered their own sexual orientations and reported the duration of time since last menses and the typical length of their fertility cycle. These data were used to estimate each woman's point in her cycle using a backward-counting method implemented in previous research (e.g., Brinsmead-Stockham et al., 2008).

\section{Results}

Accuracy and response bias were calculated using signal detection theory (e.g., Sporer, 2001). Accuracy was significantly greater than chance guessing (.50; see Table 1) and, more important, varied according to fertility status. Peak ovulation was estimated as 14 days prior to next expected menses. For women who were postpeak, the distance in time from peak ovulation was calculated by dividing the number of days postpeak by 14 , and for women who were prepeak, the number of days prepeak was divided by the difference between peak ovulation and reported cycle length (cycle length: $M=30$ days, $S D=4$ days). This yielded positive proportions for postpeak women and negative proportions for prepeak women, with peak ovulation centered at 0 .

These proportions showed a significant curvilinear relationship, such that the nearer women were to peak ovulation, the more accurate they were in judging men's sexual orientations, $F(2,36)=4.71, p=.02, R^{2}=.21$ (Fig. 1). Response bias showed a tendency for women to perceive men as straight rather than gay, but it was unrelated to the women's fertility and thus showed neither linear nor curvilinear trends, $F_{\mathrm{s}}<$ $1.86, p s>.17$.

Although our previous work found no differences in attractiveness between the gay and straight men in this stimulus set (Rule et al., 2008), perceptions of attractiveness are known to be related to women's fertility. We therefore asked 24 separate participants to judge the attractiveness of the faces along a 
Table I. Accuracy $\left(A^{\prime}\right)$ and Response Bias $\left(B^{\prime}\right)$ in Judging Sexual Orientation in Studies I Through 3

\begin{tabular}{|c|c|c|c|c|c|c|}
\hline \multirow[b]{2}{*}{ Study and condition } & \multicolumn{2}{|c|}{$A^{\prime}$} & \multirow[b]{2}{*}{$t$} & \multirow[b]{2}{*}{ Effect size $(r)$} & \multicolumn{2}{|c|}{$B^{\prime}$} \\
\hline & $M$ & $S D$ & & & $M$ & $S D$ \\
\hline Study I & .61 & .12 & $t(38)=5.52^{*}$ & .67 & .08 & .15 \\
\hline Study 2 & .61 & .06 & $t(33)=10.39 *$ & .88 & .14 & .13 \\
\hline \multicolumn{7}{|l|}{ Study 3a } \\
\hline Control & .60 & .08 & $t(18)=4.93^{*}$ & .74 & .04 & .09 \\
\hline Mating prime & .66 & .12 & $t(20)=6.13^{*}$ & .81 & .10 & .20 \\
\hline \multicolumn{7}{|l|}{ Study 3b } \\
\hline Control & .64 & .06 & $t(20)=10.88^{*}$ & .89 & .22 & .19 \\
\hline Mating prime & .63 & .07 & $t(20)=7.64^{*}$ & .81 & .20 & .17 \\
\hline
\end{tabular}

$*_{p}<.001$.

7-point scale. The judges showed consensus in their assessments (Cronbach's $\alpha=.85$ ), and the judgments were therefore averaged across raters for each target. The mean attractiveness ratings were then correlated with the dichotomous ratings of the targets as gay and straight from the main study, and these sensitivity correlations were converted using Fisher's $r$-to- $Z$ transformation to produce an estimate of the relationship between each participant's categorization and the attractiveness of the faces. The relationship between attractiveness and the categorizations of the faces was not significant $(\alpha=.05)$, as the $95 \%$ confidence interval (CI) surrounding the mean Fisher Z-transformed correlation contained $0,95 \% \mathrm{CI}=$ $[-0.03,0.07]$.

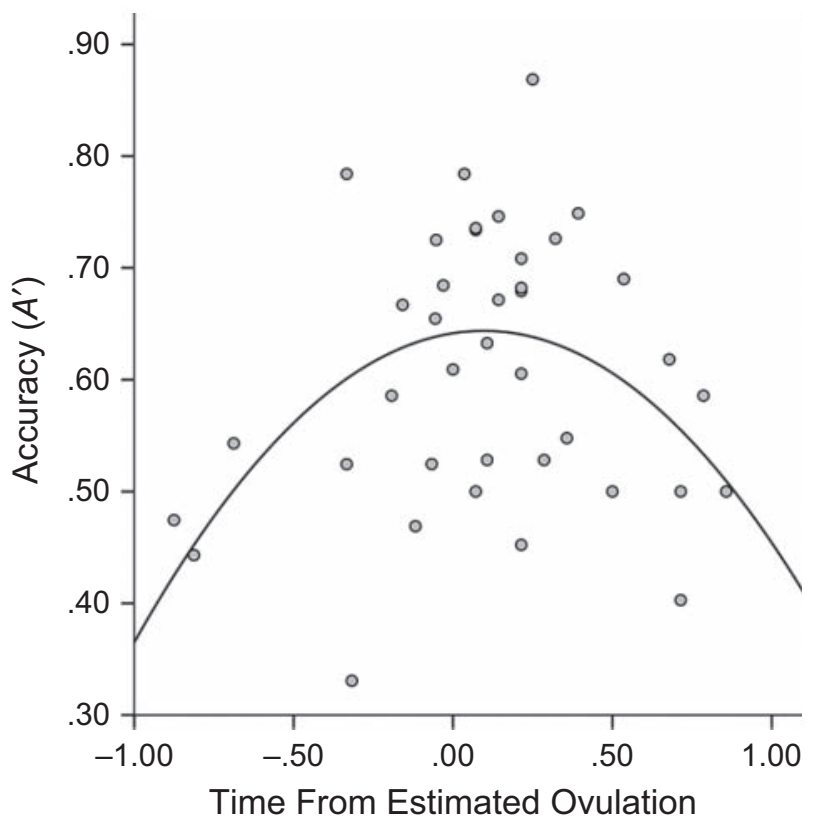

Fig. I. Results from Study I: women's accuracy $\left(A^{\prime}\right)$ in categorizing men's sexual orientations as a function of distance in time from estimated ovulation. The graph presents individual data points and a trend line showing the quadratic fit.

\section{Discussion}

Women's accuracy in judging men's sexual orientations from their faces was greater the nearer the women were to peak ovulation. Targets' sexual orientation may therefore be more salient or legible for perceivers when it is more relevant. In previous work, we found that gay men were more accurate judges of male sexual orientation than were straight men (Rule et al., 2007). This could be because gay men are more familiar or experienced with distinguishing sexual orientation, or because information about male sexual orientation is more relevant for gay men than for straight men. The present data provide some support for this relevance hypothesis. Specifically, women's success in conceiving is greater nearer to peak ovulation. One factor assisting their reproductive success is the ability to identify a suitable mate. Thus, women may be more attentive to sexual orientation nearer to ovulation because targets' candidacy as mates would be more relevant. Yet it is also possible that women may be more attentive overall to nonverbal appearance cues nearer ovulation. To investigate this possibility, Study 2 measured heterosexual women's ability to judge other women's sexual orientation from their faces.

\section{Study 2}

Thirty-four heterosexual women not using systemic contraception (cycle length: $M=30$ days, $S D=4.6$ days) were recruited as in Study 1. Procedures were identical to Study 1, with the exception that participants viewed the faces of 100 lesbian and 100 straight women. Photos were validated in earlier work (Rule et al., 2009). The photos were gray-scale images standardized for size, and none of the targets had adornments. Moreover, the lesbian and straight women did not differ in emotional expression, attractiveness, or the use of makeup.

Data were again analyzed using signal detection theory. Accuracy was significantly greater than chance guessing (Table 1) but was unrelated to participants' fertility; accuracy 
showed neither linear nor curvilinear trends, $F_{\mathrm{s}}<1.67, p \mathrm{~s}>$ .21. As in Study 1, participants tended to categorize targets as straight more often than as lesbian, and response-bias scores showed neither linear nor curvilinear relationships with fertility, $F_{\mathrm{s}}<1.31, p \mathrm{~s}>.26$. The relationship between women's fertility and accuracy in judging sexual orientation therefore appears applicable only to male targets. These data are consistent with the hypothesis that women's accuracy in judging men's sexual orientation increases nearer peak ovulation because male sexual orientation is relevant to women's reproductive success. In Study 3, we investigated this hypothesis further by using an experimental manipulation to examine women's accuracy in judging sexual orientation.

\section{Study 3}

Study 1 demonstrated that women were more accurate in judging male sexual orientation the nearer they were to peak ovulation. Study 2 demonstrated that this accuracy did not extend to female targets. Together, these findings suggest that women's accuracy may vary across the fertility cycle because men's sexual orientation is relevant to conception and thus of greater importance as women are nearer ovulation. If this hypothesis is correct, manipulating reproductive relevance should increase women's accuracy in judging male targets. Study 3 therefore compared the judgments of women primed with a mating goal with the judgments of nonprimed control subjects for both male targets (Study 3a) and female targets (Study 3b).

\section{Study 3a}

Forty women were randomly assigned to either the control condition $(n=19)$ or the mating-prime condition $(n=21)$. To prime mating goals, we asked women to read a story, borrowed from Griskevicius et al. (2007), which described a romantic encounter; this manipulation has effectively primed mating goals in past studies (Griskevicius, Cialdini, \& Kenrick, 2006; Griskevicius, Goldstein, Mortensen, Cialdini, \& Kenrick, 2006; Griskevicius et al., 2007, 2009). Apart from the prime, the stimuli and procedures for the experiment were identical to Study 1. All of the participants indicated that they were heterosexual, and the distribution of women using birth control did not differ across conditions, $\chi^{2}(1, N=40)=0.02$, $p=.90$.

Data were again calculated using signal detection theory. Women in both conditions showed accuracy that was significantly greater than chance (Table 1). It is critical to note that women primed with a mating goal were significantly more accurate than women who were not, $t(38)=2.07, p=.04, r=$ .32; see Figure 2. Thus, inducing romantic or mating-related thoughts improved accuracy in judging men's sexual orientations. Participants' response-bias scores continued to show a tendency toward categorizing men as straight, rather than gay, in both conditions; response bias did not differ across conditions, $t(38)=1.34, p=.19$. $^{1}$

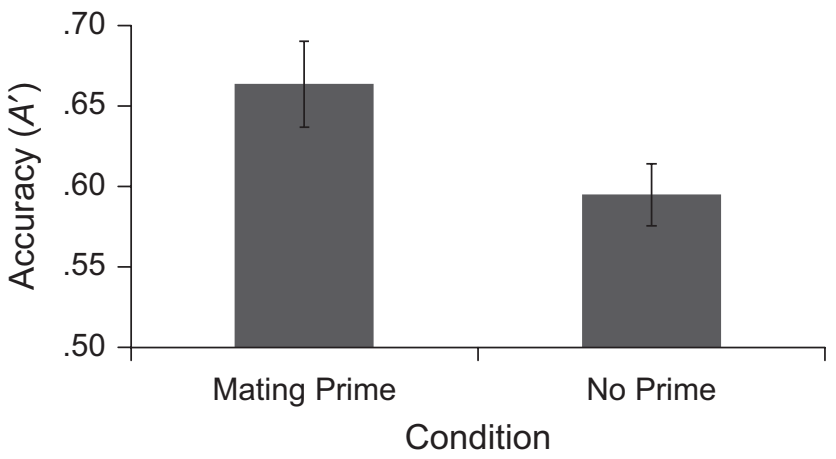

Fig. 2. Results from Study 3a: women's accuracy $\left(A^{\prime}\right)$ in categorizing men's sexual orientations as a function of condition (mating prime vs. no prime). Error bars represent standard errors.

\section{Study $3 b$}

Forty-two heterosexual women were randomly assigned to either the control condition $(n=21)$ or the mating-prime condition $(n=21)$. Procedures were the same as in Study 3a, except that participants categorized the female targets from Study 2.

Both groups were more accurate than chance in their judgments (Table 1) and did not differ according to condition in accuracy, $t(40)=0.38, p=.71$, or response bias, $t(40)=0.61$, $p=.55$. Thus, mating-related thoughts improved women's accuracy in judging male, but not female, sexual orientation.

\section{General Discussion}

As they approach peak fertility, women are significantly better at judging men's sexual orientations. In Study 1, women showed a significant relationship between their place in their fertility cycles and their accuracy in judging men's sexual orientations from their faces. Specifically, we observed a curvilinear, quadratic relationship, such that as women were nearer to peak ovulation, their accuracy in judging male sexual orientation significantly increased. This effect was not found for women's judgments of female sexual orientation in Study 2, however, and this difference suggests that fertility influences heterosexual women's attention to potential mates rather than merely increasing their sensitivity to sexual orientation or nonverbal cues more generally. Study 3 then experimentally manipulated women's interest in mates using an unobtrusive prime that has previously proven effective for inducing an interest in mating. In our study, we found that women who were primed with a mating goal were significantly more accurate in judging men's sexual orientations than were women who were not primed; however, such priming had no effect on the accuracy of their judgments of women's sexual orientations. Together, these studies suggest that a disposition toward mating increases heterosexual women's accuracy in detecting the sexual orientation of members of the opposite sex.

Much work on nonverbal behavior has attempted to examine the question of individual differences in accuracy (e.g., 
Hall \& Andrzejewski, 2008). Indeed, a large literature on the judgment of nonverbal cues has sought to understand why some individuals are better than others at making judgments in certain domains, such as deception (Bond \& DePaulo, 2008), emotion (Elfenbein \& Ambady, 2003), and interpersonal relationships (Hall \& Bernieri, 2001). Our data show that the accuracy of judgments of sexual orientation from minimal information is sensitive to both naturally occurring variations in fertility and to experimentally induced changes in thought and motivation.

In our previous work, we found that gay men more accurately judged sexual orientation than straight men did (Rule et al., 2007). One explanation for this effect is that gay men are more experienced in distinguishing sexual orientation. Another explanation is that sexual orientation is more relevant for gay men than for straight men. In the studies reported here, we showed that mating relevance influenced women's accuracy in judging sexual orientation. Thus, these data may suggest that group relevance is important for understanding in-group effects. For example, recent data have shown that group relevance influences in-group effects in perception (Hugenberg \& Corneille, 2009), memory (Rule, Garrett, \& Ambady, 2010), and emotion recognition (Young \& Hugenberg, 2010). Future work should therefore seek to dissociate the roles of in-group familiarity from in-group relevance in social cognition. Moreover, the present data suggest that the person-perception literature may also benefit from greater consideration of individual and state-based variations among perceivers, such as biological and motivational effects.

\section{Acknowledgments}

We thank Vladas Griskevicius for lending the mating-prime materials used in Study 3.

\section{Declaration of Conflicting Interests}

The authors declared that they had no conflicts of interest with respect to their authorship or the publication of this article.

\section{Note}

1. A third condition, in which 18 women were given a nonromantic prime modeled on the one borrowed from Griskevicius et al. (2007), was run post hoc. Accuracy in this condition $(M=.59, S D=.13)$ was no different from the accuracy of the women who received no prime, $t(35)=0.78, p=.44$, and was significantly lower than the accuracy of the women who were primed with the mating goal, $t(37)=2.17$, $p=.04, r=.34$.

\section{References}

Ambady, N., Hallahan, M., \& Conner, B. (1999). Accuracy of judgments of sexual orientation from thin slices of behavior. Journal of Personality and Social Psychology, 77, 538-547.

Ambady, N., \& Rosenthal, R. (1993). Half a minute: Predicting teacher evaluations from thin slices of nonverbal behavior and physical attractiveness. Journal of Personality and Social Psychology, 64, 431-441.
Bond, C. F., Jr., \& DePaulo, B. M. (2006). Accuracy of deception judgments. Personality and Social Psychology Bulletin, 10, 214-234.

Bond, C. F., Jr., \& DePaulo, B. M. (2008). Individual differences in judging deception: Accuracy and bias. Psychological Bulletin, 134, 477-492.

Brewer, M. B. (1988). A dual process model of impression formation. In R. S. Wyer, Jr., \& T. K. Srull (Eds.), A dual model of impression formation (Advances in Social Cognition Vol. 1, pp. 1-36). Hillsdale, NJ: Erlbaum.

Brinsmead-Stockham, K., Johnston, L., Miles, L., \& Macrae, C. N. (2008). Female sexual orientation and menstrual influences on person perception. Journal of Experimental Social Psychology, 44, 729-734.

Collins, M. A., \& Zebrowitz, L. A. (1995). The contributions of appearance to occupational outcomes in civilian and military settings. Journal of Applied Social Psychology, 25, 129-163. doi:10.1111/j.1559-1816.1995.tb01588.x

Elfenbein, H. A., \& Ambady, N. (2003). Universals and cultural differences in recognizing emotions. Current Directions in Psychological Science, 12, 159-164.

Griskevicius, V., Cialdini, R. B., \& Kenrick, D. T. (2006). Peacocks, Picasso, and parental investment: The effects of romantic motives on creativity. Journal of Personality and Social Psychology, 91, 63-76.

Griskevicius, V., Goldstein, N. J., Mortensen, C. R., Cialdini, R. B., \& Kenrick, D. T. (2006). Going along versus going alone: When fundamental motives facilitate strategic (non)conformity. Journal of Personality and Social Psychology, 91, 281-294.

Griskevicius, V., Tybur, J. M., Gangestad, S. W., Perea, E. F., Shapiro, J. R., \& Kenrick, D. T. (2009). Aggress to impress: Hostility as an evolved context-dependent strategy. Journal of Personality and Social Psychology, 96, 980-994.

Griskevicius, V., Tybur, J. M., Sundie, J. M., Cialdini, R. B., Miller, G. F., \& Kenrick, D. T. (2007). Blatant benevolence and conspicuous consumption: When romantic motives elicit strategic costly signals. Journal of Personality and Social Psychology, 93, 85-102.

Hall, J. A., \& Andrzejewski, S. A. (2008). Who draws accurate first impressions? Personal correlates of sensitivity to nonverbal cues. In N. Ambady \& J. Skowronski (Eds.), First impressions (pp. 87-105.). New York, NY: Guilford.

Hall, J. A., \& Bernieri, F. J. (2001). Interpersonal sensitivity: Theory and measurement. Mahwah, NJ: Erlbaum.

Hugenberg, K., \& Corneille, O. (2009). Holistic processing is tuned for in-group faces. Cognitive Science, 33, 1173-1181.

Johnston, L., Arden, K., Macrae, C. N., \& Grace, R. C. (2003). The need for speed: The menstrual cycle and person construal. Social Cognition, 21, 89-100.

Jones, B. C., DeBruine, L. M., Perrett, D. I., Little, A. C., Feinberg, D. R., \& Law Smith, M. J. (2008). Effects of menstrual cycle phase on face preferences. Archives of Sexual Behavior, 37, 78-84.

Lieberman, M. D., \& Rosenthal, R. (2001). Why introverts can't always tell who likes them: Multitasking and nonverbal decoding. Journal of Personality and Social Psychology, 80, 294-310. 
Macrae, C. N., Alnwick, K. A., Milne, A. B., \& Schloerscheidt, A. M. (2002). Person perception across the menstrual cycle: Hormonal influences on social-cognitive functioning. Psychological Science, 13, 532-536.

Macrae, C. N., \& Bodenhausen, G. V. (2000). Social cognition: Thinking categorically about others. Annual Review of Psychology, 51, 93-120.

Penton-Voak, I. S., Perrett, D. I., Castles, D. L., Kobayashi, T., Burt, D. M., Murray, L. K., \& Minamisawa, R. (1999). Menstrual cycle alters face perception. Nature, 399, 741-742.

Provost, M. P., Troje, N. F., \& Quinsey, V. L. (2008). Short-term mating strategies and attraction to masculinity in point-light walkers. Evolution \& Human Behavior, 29, 65-69.

Rule, N. O., \& Ambady, N. (2010). First impressions of the face: Predicting success and behavior. Social and Personality Psychology Compass, 4, 506-516.

Rule, N. O., Ambady, N., Adams, R. B., Jr., \& Macrae, C. N. (2007). Us and them: Memory advantages in perceptually ambiguous groups. Psychonomic Bulletin \& Review, 14, 687-692.
Rule, N. O., Ambady, N., Adams, R. B., Jr., \& Macrae, C. N. (2008). Accuracy and awareness in the perception and categorization of male sexual orientation. Journal of Personality and Social Psychology, 95, 1019-1028.

Rule, N. O., Ambady, N., \& Hallett, K. C. (2009). Female sexual orientation is perceived accurately, rapidly, and automatically from the face and its features. Journal of Experimental Social Psychology, 45, 1245-1251.

Rule, N. O., Garrett, J. V., \& Ambady, N. (2010). Faces and places: Geographic environment influences the ingroup memory advantage. Journal of Personality and Social Psychology, 98, 343-355.

Sporer, S. L. (2001). Recognizing faces of other ethnic groups: An integration of theories. Psychology, Public Policy, and Law, 7, 36-97.

Young, S. G., \& Hugenberg, K. (2010). Mere social categorization modulates identification of facial expressions of emotion. Journal of Personality and Social Psychology, 99, 964-977. doi:10.1037/a0020400

Zebrowitz, L. A., \& McDonald, S. M. (1991). The impact of litigants' baby-facedness and attractiveness on adjudications in small claims courts. Law and Human Behavior, 15, 603-623. 